\title{
A Straightforward Mathematical Model of Hot Metal Desulphurization
}

\author{
Miguel A. Barron, Dulce Y. Medina, Joan Reyes \\ Departamento de Materiales, Universidad Autonoma Metropolitana Azcapotzalco, Mexico City, Mexico \\ Email: bmma@correo.azc.uam.mx, dyolotzin@azc.uam.mx, joremi@azc.uam.mx
}

How to cite this paper: Barron, M.A., Medina, D.Y. and Reyes, J. (2020) A Straightforward Mathematical Model of Hot Metal Desulphurization. Open Journal of Applied Sciences, 10, 318-327. https://doi.org/10.4236/ojapps.2020.106024

Received: May 21, 2020

Accepted: June 25, 2020

Published: June 28, 2020

Copyright $\odot 2020$ by author(s) and Scientific Research Publishing Inc. This work is licensed under the Creative Commons Attribution International License (CC BY 4.0).

http://creativecommons.org/licenses/by/4.0/

(c) (i) Open Access

\begin{abstract}
A straightforward kinetic model for the hot metal desulphurization process is presented. The model contains some of the most important parameters and variables that govern the process. The inputs, outputs and parameters of a desulphurization program employed at industry are discussed. The model is able to cope with different injection policies of desulphurizers such as monoinjection, co-injection or multi-injection. When compared to the rotary impeller method, results of this model shows that the weight of lime consumed in the lance injection method is lesser than that consumed in the rotary impeller method for the same conditions of the hot metal charge.
\end{abstract}

\section{Keywords}

Desulphurization, Hot Metal, Kinetic Model, Lance Injection, Rotary Impeller

\section{Introduction}

Commonly, sulphur is considered a harmful impurity in steels. Sulphur is undesirable in most of applications of steel due to these reasons: it affects negatively the internal and surface quality of steel products, contributes to the steel brittleness at high temperatures, behaves as a stress raiser, fosters granular weakness and cracks during solidification, adversely affects the mechanical properties of steel, and it lowers the melting point and intergranular strength of steel [1].

Hot metal is an important raw material to produce crude steel and is obtained in the blast furnace. It contains around $4 \%$ (weight percent) of carbon, $1 \%$ silicon $0.5 \%$ manganese, $0.05 \%$ phosphorus, $0.05 \%$ sulphur, and the rest is iron. Phosphorus and sulphur are considered impurities. Hot metal is transformed into steel in the basic oxygen furnace (BOF) by oxidation of its constituents with 
oxygen and iron ore, except sulphur, given that sulphur requires reductive conditions. Consequently, sulphur must be removed in the transfer ladle or torpedo car before the processing of hot metal in the BOF.

Currently, at industry three methods are employed to carry out the desulphurization of hot metal, and they are depicted in Figure 1 [2]. In the lance injection method, Figure 1(a), a powdered desulphurization reagent (lime, calcium carbide or magnesium) or a mixture of them, is driven by an inert carrier gasusually nitrogen or argon-into the hot metal through a ceramic lance with one or more nozzles located at the tip. The gas bubbles, with the desulphurizer particles adhered to them, ascend due to buoyancy forces to the hot metal surface, and during their ascending trajectory those particles chemically react with the sulphur dissolved in the hot metal. Sulphides formed ascend too and are collected at the top slag. To prevent resulphurization the top slag is mechanically removed after the process in a slag skimming machine. The residence time of the particles and the chemical kinetic are important factors which determine the efficiency of the desulphurization process.

Figure 2(b) depicts the rotary impeller method, where a desulphurizer, usually just lime, is added to the ladle in a batch or a continuous feed. The refractorymade rotary impeller, with a rotation speed around $100 \mathrm{rpm}$, produces a strong stirring action in the hot metal and, as a consequence, an intimate contact between the hot metal and the desulphurizer is obtained. As in the injection method, the desulpurizer particles chemically react with the hot metal sulphur and the resulting sulphides are collected at the top slag. Due to the strong stirring action of the rotary impeller, no carrier gas is required. However, the mixing power of the impeller depends on its design, its rotation speed, and its immersion depth.

The bottom injection method is sketched in Figure 1(c). In this method, the powdered desulphurizer is injected into the hot metal using an inert carrier gas, usually nitrogen or argon, through a porous plug located at the bottom of the ladle. The desulphurization mechanism of the bottom injection method is identical to that described above for the injection method. As in the injection method, the residence time of bubbles and particles in the hot metal is inversely proportional to their size.

A very recent and complete review on modeling of hot metal desulphurization is presented in [3]. In accordance to these authors mathematical models for reaction kinetics have evolved from simplistic rate equations to more complex phenomenon-based models. In industrial scale applications data-driven approaches have also been proposed with the purpose of obtaining better predictive performance. Besides, it is reported that bath mixing has been studied in the last years using physical and numerical simulations to optimize mixing conditions in ladles and torpedo cars.

On the other hand, continuous efforts have been made in recent years from industry and academy to carry out the improvement, optimization and automation 


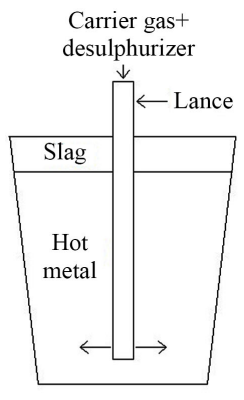

(a)

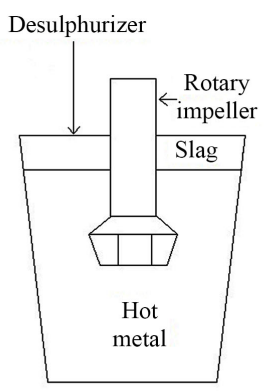

(b)

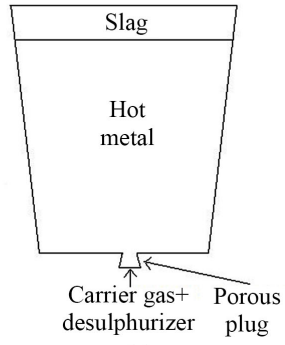

(c)

Figure 1. Three methods of hot metal desulphurization. (a) Lance injection; (b) Rotary impeller; (c) Bottom injection [2].

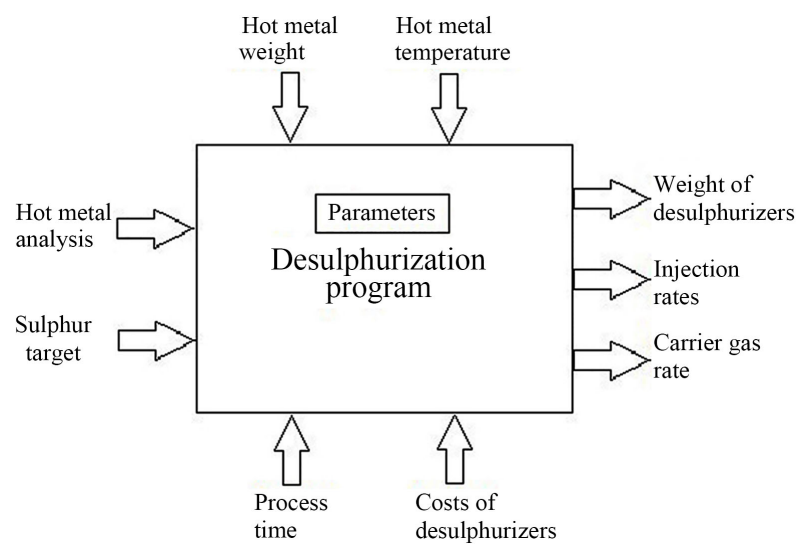

Figure 2. Inputs and outputs of a desulphurization program for control purposes.

of the above desulphurization methods. Related to the injection method, in [4] it is reported the design of a Personal Computer based system to optimize the lance injection through automatic selection of the desulphurizer reagents. In [5] the effect of blowing of propane gas mixed with nitrogen on hot metal desulphurization was investigated. New lance designs have been proposed in [6]. Here, several lance configurations were modeled and simulated to obtain the most efficient design using physical and mathematical modeling. The rotary impeller method for hot metal desulphurization has been extensively studied in the last years. A wide variety of topics have been considered, among others: variable velocity stirring [7], coupled thermo-fluid stress analysis of the impellers at extremely high temperatures [8], a kinetic model that considers the contribution of dispersed particles of desulphurizing agent [2], use of residual mixtures of aluminum dross, fluorspar, and lime in the hot metal desulphurization [9], the effect of flux dispersion on the desulphurization reaction [10], effect of the flux addition method [11], and the use of residual marble, lime and fluorspar mixtures [12].

Complex mathematical models for hot metal desulphurization look great on paper but soon will end up in the wastepaper basket in industrial environments 
[13]. In this work a straightforward kinetic model for the hot metal desulphurization process is presented. This model contains the most important parameters and variables that govern the above process. From this model a desulphurization program for plant staff training could be elaborated given that the model considers fundamental parameters employed in daily plant operations. The inputs, outputs and parameters of a desulphurization program employed at industry are discussed. Besides, the model is able to cope with different injection policies such as mono-injection, co-injection or multi-injection. Using computer simulations, the model was successfully applied to a hot metal charge that was desulphurized with the rotary impeller method reported in the literature. Numerical results show that using this model the sulphur target could be reached within the same process time for both processes, but the lance injection requires lesser lime consumption than the rotary impeller.

\section{The Mathematical Model}

A mathematical model of the hot metal desulphurization which would be dedicated to process control or staff training must include the essential variables and parameters which rule the process. The model must ensure that the target final sulphur content is achieved regardless the desulphurization reagent or the injection method employed [4]. That model must not be so oversimplified that yields poor predictions or bad control actions, nor so complex which prevents its usage in real plant applications by the staff or available computer equipment. In accordance to [13], complex elegant control systems and mathematical models look great on paper but soon will end up on "manual" in industrial environments.

Once the mathematical model is developed taking into account the above remarks, a computer program can be made. Figure 2 is a block diagram which shows the inputs and outputs of a desulphurization program for control purposes [4]. The input variables are: hot metal weight, hot metal temperature, hot metal analysis, final (target) sulphur content, injection time, and cost of desulphurizers [4]. On the other hand, the output variables are: weight of desulphurizers, injection rates, policy of injection of desulphurizers, and carrier gas flow rate [4]. Some of the parameters of the program are as follows: particle diameter, hot metal density, density of desulphurizers, carrier gas density, hot metal viscosity, bubble diameter, lance immersion depth, and so on. The mass transfer coefficient and the reaction rate (kinetic) constant are calculated from the mathematical model.

Nowadays, lime $(\mathrm{CaO})$, calcium carbide $\left(\mathrm{CaC}_{2}\right)$ and magnesium $(\mathrm{Mg})$ are the most employed desulphurizers in the steel industry, and they remove the sulphur dissolved in hot metal by chemical reaction, as follows [1]:

$$
\begin{gathered}
\mathrm{CaO}+[\mathrm{S}] \rightarrow(\mathrm{CaS})+[\mathrm{O}] \\
\mathrm{CaC}_{2}+[\mathrm{S}] \rightarrow(\mathrm{CaS})+2[\mathrm{C}] \\
\mathrm{Mg}+[\mathrm{S}] \rightarrow(\mathrm{MgS})
\end{gathered}
$$


The calcium and magnesium sulphides formed during the above chemical reactions ascend through the molten metal and are collected in the top slag. The sulphide and the desulphurizer particles ascend by themselves (rotary impeller method) or attached to the bubbles of the carrier gas (lance and bottom injection methods) due to buoyancy forces because the bubble density is lesser than the hot metal density. The residence time of the desulphurizer particles in the hot metal is an important factor that determines the efficiency of the desuphurization process given that the residence time determines the reaction time. As the bubble size and the desulphurizer particle diameter are smaller, the residence time will be bigger.

Irrespective of the desulphurization method or the desulphurizer employed, the desulphurization reactions are first order chemical reaction whose kinetics is expressed as follows [14]:

$$
\frac{\mathrm{d} S}{\mathrm{~d} t}=-k\left(S-S_{e}\right)
$$

where $S$ is the sulfur concentration in the hot metal, $t$ is time, $k$ is the reaction rate constant, and $S_{e}$ is the sulphur concentration at thermodynamic equilibrium. It must be remarked that the value of $k$ depends, among others, on a lot of operational factors, such as: the kind of desulphurizer employed, the density and the mass flow rate of the desulphurizers, the mass and temperature of the hot metal, the residence time, the particle diameter, the density and the flow rate of the carrier gas, the bubble size, the density and the viscosity of the hot metal, the lance immersion depth, the geometry of the lance, the geometry and rotation speed of the impeller, the impeller immersion depth, and so on.

Integration of Equation (1) gives

$$
S(t)=S_{e}+\left(S_{0}-S_{e}\right) \mathrm{e}^{-k t}
$$

where $S_{0}$ is the initial sulphur concentration in the hot metal. For the lance injection method using lime as desulphurizer, the reaction rate constant can be estimated from the expression [15]:

$$
k=\frac{6 \beta \tau_{r} \dot{w}_{\mathrm{CaO}} \rho_{m}}{d_{p} w_{m} \rho_{\mathrm{CaO}}}
$$

where $\beta$ is the mass transfer coefficient, $\tau_{r}$ is the residence time, $\dot{w}_{\mathrm{CaO}}$ is the mass flow rate of lime, $\rho_{m}$ is the hot metal density, $d_{p}$ is lime particle diameter, $W_{m}$ is the hot metal mass, and $\rho_{\text {CaO }}$ is the lime density.

Dependence of the reaction rate constant on temperature is ruled by an Arrhenius behavior [16]:

$$
k(T)=k_{0} \mathrm{e}^{-\frac{E_{a}}{R T}}
$$

where $k_{0}$ is the pre-exponential factor, $E_{a}$ is the activation energy for the reaction, $R$ is universal gas constant, and $T$ is the absolute temperature.

For simultaneous injection of two or more desulphurizers, i.e. co-injection or 
multi-injection, a method for calculation the average value of the reaction rate constant for the mixture is estimated from the weighting of the molar fraction and the reaction rate constant of each desulphurizer, as follows [17]:

$$
k_{a v}=\sum_{i=1}^{n} x_{i} k_{i}
$$

where $k_{a v}$ is the average value of the reaction rate constant for the mixture, $n$ is the number of desulphurizers injected, and $x_{i}$ and $k_{i}$ are the molar fractions and the rate constants of the $\mathrm{i}^{\text {th }}$ desulphurizer, respectively. Approximate values of the reaction rate constant for $\mathrm{CaO}, \mathrm{CaC}_{2}$ and $\mathrm{Mg}$ are found in [17].

For the lance injection method, the residence time of the desulphurizer particles and carrier gas bubbles can be estimated considering that particles and bubbles rise in straight line along the injection lance. If the particle diameter is much less than the bubble diameter, as is usually the case, the particles stick to the bubbles and rise at the bubble velocity. Then, the residence time $\tau_{r}$ is estimated as follows:

$$
\tau_{r}=\frac{h_{i}}{v_{b}}
$$

where $h_{i}$ is the lance immersion depth and $v_{b}$ is the rise velocity of particles and bubbles. In the case of the bottom injection method, $h_{i}$ is equal to the hot metal height in the ladle, which corresponds to the distance between the bottom of the ladle and the surface in contact with the stop slag. For the rotary impeller method, particles and bubbles are moving in an upward spiral path, which strongly depends on the rotation speed, the impeller immersion depth, the size of the particles and the physical properties of the particles and hot metal. The rise velocity of the gas bubbles is ruled by the Stoke's law [14]:

$$
v_{b}=\frac{g\left(\rho_{m}-\rho_{g}\right) d_{b}^{2}}{18 \mu_{m}}
$$

where $g$ is the gravitational acceleration, $\rho_{g}$ is the carrier gas density, $d_{b}$ the bubble diameter, and $\mu_{m}$ is the hot metal density.

The process time, as is assumed here, is the duration of the desulphurization treatment, and corresponds to the injection time or the stirring time, in accordance with the desulphurization method employed. The process time is set by the plant staff considering the overall time scheduling of the blast furnace and the oxygen converter, and the production conditions [4]. The process time must be short given that the effectiveness of the desulphurization process is inversely proportional to the mass flow rate of the desulphurizers [1].

Once the process time $\tau_{p}$ is set, the required reaction rate constant of the process $k_{p}$ is estimated from Equation (2):

$$
k_{p}=\frac{1}{\tau_{p}} \log \left(\frac{S_{0}-S_{e}}{S_{t}-S_{e}}\right)
$$


where $S_{t}$ is the sulphur concentration target, or desired final sulphur content.

When lime is employed as desulphurizer, the required mass flow rate is obtained from Equations (3) and (6):

$$
\dot{w}_{\text {CaO }}=\frac{k_{p} d_{p} w_{m} v_{b} \rho_{\text {CaO }}}{6 \beta h_{i} \rho_{m}}
$$

If the lime mass flow rate is kept constant during the process, the weight of lime to employ is estimated as follows:

$$
w_{\mathrm{CaO}}=\dot{w}_{\mathrm{CaO}} \tau_{p}
$$

The diameter of the gas bubbles can be estimated from the expression [18]:

$$
d_{b}=\left[\frac{6 d_{n} \sigma}{g\left(\rho_{m}-\rho_{g}\right)}\right]^{1 / 3}
$$

where $d_{n}$ is the diameter of the lance nozzles, and $\sigma$ is the hot metal surface tension.

As is seen in Figure 2, the selection of a particular desulphurizer, or a mixture of desulphurizers, depends on several plant factors, such as: sulphur initial content, sulphur targt, process time, hot metal temperature, cost of desulphurizers, weight of hot metal, and so on. Lime is available everywhere and is the cheapest desulphurizer. Calcium carbide and magnesium are efficient desulphizers, but they are expensive and present severe security and environmental risks, therefore these reagents must be employed only when fast desulphurization or very low final sulphur content are desired.

\section{Application Example}

The above mathematical model was previously validated by the present authors in [17] using the results reported in [15] for the desulfurization of hot metal through the injection method using just lime as desulphurizer. In this work the present model was applied to the plant data reported in [2] for a rotary impeller process, whose values are shown in Table 1.

For both processes the mass of hot metal, the initial sulphur, the target sulphur and the process time are identical. Using the data of Table 2 for the proposed model, Equation (8) yields $k_{p}=0.003669 \mathrm{~s}^{-1}\left(0.2202 \mathrm{~min}^{-1}\right)$. When applied to the plant data reported in [2] the present model produces the results shown in Figure 3. This figure shows an exponential decay of the sulphur concentration, according to Equation (2), considering null the sulphur concentration at thermodynamic equilibrium. The present model requires a lime mass flow rate $\dot{w}_{\text {CaO }}$ $=0.00833 \mathrm{~kg} \cdot \mathrm{s}^{-1} \cdot$ tonne $^{-1}$, which represents a specific lime consumption of 6.15 $\mathrm{kg} \cdot$ tonne $^{-1}$ or a total added lime of $1845 \mathrm{~kg}$. It is appreciated that the injection lance method requires $1845 \mathrm{~kg}$ of lime, whereas the rotary impeller method requires $2223 \mathrm{~kg}$ of lime, to obtain a sulphur target of $2 \mathrm{ppm}$ for a charge consisting of 300 tons of hot metal, $30 \mathrm{ppm}$ of initial sulphur and $12.3 \mathrm{~min}$ of process time. 


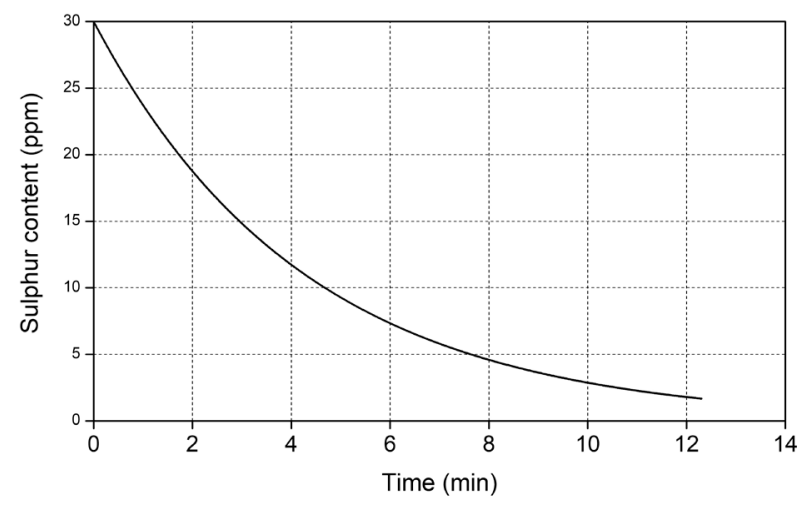

Figure 3. Time evolution of the sulphur concentration for hot metal charges reported in [2] using the present desulphurization model with the data of Table 2.

Table 1. Average data values in a rotary impeller process [2].

\begin{tabular}{cc}
\hline Mass of hot metal & 300 metric tonnes \\
\hline Initial sulphur & $30 \mathrm{ppm}$ (parts per million) \\
Target sulphur & $2 \mathrm{ppm}$ \\
Impeller rotation speed & $100 \mathrm{rpm}$ \\
Total added flux (90\% lime, 10\% CaF2) & $2470 \mathrm{~kg}($ lime $2223 \mathrm{~kg})$ \\
Specific flux consumption & $8.1 \mathrm{~kg} \mathrm{ton}^{-1}$ \\
Specific lime consumption (calculated) & $7.41 \mathrm{~kg} \mathrm{tonne}^{-1}$ \\
Process time & $12.3 \mathrm{~min}^{2}$
\end{tabular}

Table 2. Data employed in the present lance injection model.

\begin{tabular}{cc}
\hline Mass transfer coefficient & $6.3 \times 10^{-5} \mathrm{~m} \mathrm{~s}^{-1}$ \\
\hline Hot metal density & $7100 \mathrm{~kg} \mathrm{~m}^{-3}$ \\
Lime density & $3345 \mathrm{~kg} \mathrm{~m}^{-3}$ \\
Carrier gas density & $1.1650 \mathrm{~kg} \mathrm{~m}^{-3}$ \\
Lime particle diameter & $1.0 \times 10^{-4} \mathrm{~m}$ \\
Gas bubble diameter & $2.98 \times 10^{-4} \mathrm{~m}$ \\
Lance immersion depth & $3 \mathrm{~m}$ \\
Gravity acceleration & $9.81 \mathrm{~m} \mathrm{~s}{ }^{-2}$ \\
Hot metal viscosity & $0.0067 \mathrm{~kg} \cdot \mathrm{m}^{-1} \cdot \mathrm{s}^{-1}$ \\
Mass of hot metal & $300,000 \mathrm{~kg}$ \\
Initial sulphur & $30 \mathrm{ppm}$ \\
Target sulphur & $2 \mathrm{pmm}$ \\
Process time & $738 \mathrm{~s}(12.3 \mathrm{~min})$ \\
Equilibrium sulphur & $0 \mathrm{ppm}$ \\
&
\end{tabular}




\section{Conclusion}

A straightforward kinetic mathematical model of the hot metal desulphurization process is presented. This model includes some of the most important parameters and variables that govern the lance injection method. This suggests that, potentially, the model could be employed for plant staff training. The model is able to cope with different injection policies such as mono-injection, co-injection and multi-injection. Besides, it allows the comparison among different hot metal desulphurization methods in terms of weight of desulphurizers consumed and injection rates for identical hot metal charges, process time and final sulphur contents. When compared to the rotary impeller method using lime as desulphurizer, the model shows that the weight of lime consumed in the lance injection method is lesser than that consumed in the rotary impeller method for the same hot metal charge.

\section{Conflicts of Interest}

The authors declare no conflicts of interest regarding the publication of this paper.

\section{References}

[1] https://www.ispatguru.com/desulphurization-of-hot-metal/

[2] Da Silva, C., Da Silva, I., Leao, V. and Rocha, L. (2009) A Kinetic Model Applied to Pig Iron Desulfurization in the Kanbara Reactor. Molten 2009: Proceedings of the VIII International Conference on Molten Slags, Fluxes \& Salts, Santiago, 18-21 January 2009, 737-749.

[3] Visuri, V.V., Vuolio, T., Haas, T. and Fabritius, T. (2020) A Review of Modeling Hot Metal Desulfurization. Steel Research International, 91, Article ID: 1900454. https://doi.org/10.1002/srin.201900454

[4] http://www.millennium-steel.com/wp-content/uploads/articles/pdf/2004/pp80-84\% 20MS04.pdf

[5] Kikuchi, N., Nabeshima, S. and Kishimoto, Y. (2012) Effect of Propane Gas on Hot Metal Desulfurization by CaO Based Flux. ISIJ International, 52, 1809-1816.

[6] Tripathi, P., Kumar, D.S., Sah, R. and Sekhar, V.R. (2016) An Improved Lance Design for Hot Metal Desulphurisation. Ironmaking \& Steelmaking, 2016, 1-9.

[7] Ji, J., Liang, R. and He, J. (2016) Simulation on Mixing Behavior of Desulfurizer and High-Sulfur Hot Metal Based on Variable-Velocity Stirring. ISIJ International, 56, 794-802.

[8] Huang, D. and Huang, F. (2014) Coupled Thermo-Fluid Stress Analysis of Kambara Reactor with Various Anchors in the Stirring of Molten Iron at Extremely High Temperatures. Applied Thermal Engineering, 73, 220-226. https://doi.org/10.1016/j.applthermaleng.2014.07.042

[9] Mahendra, K.C., Virupaksha, G.H., Adarsha, K., Muniswami, K., Kurubara H. and Shivaraj, R.N. (2017) Hot Metal De-Sulphurisation by KR Process. International Journal for Research in Applied Science \& Engineering Technology, 5, 1556-1565.

[10] Nakai, Y., Sumi, I., Matsuno, H., Kikuchi, N. and Kishimoto, Y. (2010) Effect of Flux Dispersion Behavior on Desulfurization of HotMetal. ISIJ International, 50, 
403-410.

[11] Nakai, Y., Hino, Y., Sumi, I., Kikuchi, N., Uchida, Y. and Miki, Y. (2015) Effect of Flux Addition Method on Hot Metal Desulfurization by Mechanical Stirring Process. ISIJ International, 55, 1398-1407.

[12] Nylo, F., Fardin, F., Soares, J. and De Oliveira, J. (2012) Hot Metal Desulfurization by Marble Waste and Fluorspar. Revista Escola de Minas, 65, 233-239. https://doi.org/10.1590/S0370-44672012000200012

[13] Luyben, W.L. (1999) Process Modeling, Simulation, and Control for Chemical Engineers. McGraw-Hill, New York.

[14] Ghosh, A. (2001) Secondary Steelmaking. CRC Press, Boca Raton.

[15] Oeters, F. (1989) Metallurgy of Steelmaking. Springer-Verlag, Berlin.

[16] Levenspiel, O. (1999) Chemical Reaction Engineering. John Wiley \& Sons, New York.

[17] Barron, M.A., Hilerio, I. and Medina, D.Y. (2015) Modeling and Simulation of Hot Metal Desulphurization by Powder Injection. Open Journal of Applied Sciences, 5 , 295-303. https://doi.org/10.4236/ojapps.2015.56030

[18] Szekely, J. (1979) Fluid Flow Phenomena in Metals Processing. Academic Press, New York. 